\title{
STRATEGI PEMASARAN CV DIANA PHON BOGOR DENGAN PENDEKATAN STAKEHOLDER ENGAGEMENT STRATEGY
}

\section{MARKETING STRATEGY OF CV DIANA PHON BOGOR WITH STAKEHOLDER ENGAGEMENT STRATEGY APPROACH}

\author{
Tjedahwati*, Rizal Syarief, dan Hartrisari Hardjomidjojo \\ Program Pascasarjana Manajemen dan Bisnis, Sekolah Bisnis Institut Pertanian Bogor \\ Kampus IPB Gunung Gede 16151, Bogor , Indonesia \\ email: tjedahwatirusdi@gmail.com \\ Makalah: Diterima 13 April 2018; Diperbaiki 10 Agustus 2018; Disetujui 23 Agustus 2018
}

\begin{abstract}
CV Diana Phon Bogor is a small business in trading sector by selling various kinds of agricultural productssuch as pesticides, fertilizers, plant seeds, pots, and agricultural tools. Sales of CV Diana Phon Bogor in the last three years (2014-2016) have been decreased, it needs a new and right strategy to increase the sales. The purpose of this research was to design a marketing strategy for CV Diana Phon, Bogor. This research used the stakeholder engagement strategy method. Stakeholder engagement strategy sees involvement between stakeholders, in this case CV Diana Phon Bogor with suppliers and consumers. This research used descriptive approach that interviewed the owner and used questionnaire for suppliers and consumers. Stakeholder analysis results showed that $66.7 \%$ of suppliers were in engage category and $76.7 \%$ of consumers were in engage category. This showed that the stakeholders associated with CV Diana Phon Bogor were loyal. The design of marketing strategy undertaken was to maintain good relationships with stakeholders, in this case suppliers and consumers.
\end{abstract}

Keyword: engagement, marketing, stakeholder, startegy

\section{ABSTRAK}

CV Diana Phon Bogor adalah usaha kecil yang bergerak di sektor perdagangan. Usaha kecil ini menjual produk-produk penunjang pertanian yaitu alat-alat pertanian, bibit tanaman, pestisida, pot, dan pupuk. CV Diana Phon Bogor mengalami penurunan penjualan dalam kurun waktu 3 tahun terakhir (2014-2016). Tujuan penelitian ini yaitu untuk merancang strategi pemasaran CV Diana Phon Bogor. Penelitian ini menggunakan metode stakeholder engagement strategy. Stakeholder engagement strategy melihat keterlibatan antar pemangku kepentingan, dalam hal ini CV Diana Phon Bogor dengan pemasok dan konsumen. Penelitian ini menggunakan pendekatan deskriptif dengan teknik pengumpulan data yaitu wawancara dengan pemilik usaha dan kuisioner untuk pemasok dan konsumen. Hasil analisis stakeholder menunjukan 66,7\% pemasok masuk ke kategori engage dan 76,7\% konsumen masuk ke kategori engage. Hal ini menunjukkan pemangku kepentingan yang berhubungan dengan CV Diana Phon Bogor termasuk loyal. Perancangan strategi pemasaran yang dilakukan yaitu menjaga hubungan baik dengan pemangku kepentingan, dalam hal ini pemasok dan konsumen.

Kata Kunci: engagement, pemangku kepentingan, pemasaran, strategi

\section{PENDAHULUAN}

CV Diana Phon Bogor merupakan salah satu usaha kecil yang bergerak pada sektor perdagangan dengan menjual keperluan pertanian yaitu pestisida, pupuk, pot dan polybag, bibit tanaman, dan alat-alat pertanian. Penjualan CV Diana Phon Bogor dalam tiga tahun terakhir (20122016) mengalami penurunan. Penurunan penjualan tersebut disajikan pada Tabel 1 .

Penurunan penjualan tersebut disebabkan oleh faktor internal dan eksternal yang ada pada CV Diana Phon Bogor. Faktor internal yang menyebabkan turunnyan penjualan yaitu syarat penjualan, modal, dan kondisi organisasi. Faktor eksternalnya yaitu melemahnya perekonomian Indonesia pada 2014-2016. Data yang diperoleh dari
BPS (2015) menyebutkan bahwa pada 2014 ekonomi Indonesia tumbuh sebesar 5,02\%, dimana angka tersebut lebih kecil dibanding pada 2013 sebesar 5,58\%. Ekonomi Indonesia pada 2015 sebesar 4,79\% (BPS, 2016). Pemerintah memangkas anggaran subsidi BBM dan elpiji dari Rp 240 triliun menjadi Rp 60,8 triliun pada 2015. Pada 2016 pemerintah kembali memangkas subsidi BBM dan elpiji menjadi Rp 43,4 Triliun (Investor Daily Indonesia, 2018). Dipangkasnya anggaran subsidi BBM dan elpiji tersebut menyebabkan harga BBM dan elpiji naik, dimana kenaikan tersebut akan berdampak pada harga barang lainnya. Hal tersebut menyebabkan masyarakat menjadi enggan untuk membelanjakan uang yang dimilikinya, sehingga daya beli masyarakat menurun. Dampaknya akan terasa pula pada usaha kecil sejenis CV Diana Phon 
Bogor, yaitu usaha-usaha yang bergerak di sektor perdagangan.

Tabel 1. Total penjualan CV Diana Phon Bogor tahun 2014-2017

\begin{tabular}{cc}
\hline Tahun & Total Penjualan \\
\hline 2014 & Rp 591.566.558 \\
2015 & Rp 504.644.657 \\
2016 & Rp 487.916.232 \\
2017 & Rp 471.684.012 \\
\hline
\end{tabular}

Sumber : Laporan Penjualan CV Diana Phon Bogor (2017)

CV Diana Phon Bogor memiliki peluang untuk dapat meningkatkan kembali penjualannya. Peluang tersebut dapat dilihat dari sektor perdagangan dan pertanian yang ada pada CV Diana Phon Bogor. CV Diana Phon Bogor termasuk dalam UMKM (Usaha Mikro, Kecil, Menengah). UMKM memiliki kontribusi besar terhadap pertumbuhan ekonomi di Indonesia. Sumbangan UMKM terhadap PDB pada tahun 2016 sebesar 60,34\%. Sumbangan tersebut mengalami kenaikan dari yang sebelumnya sebesar 57,84\% (Kementerian Perindustrian RI, 2016). Profil bisnis UMKM terdiri dari beberapa sektor yaitu sektor perdagangan, sektor industri pengolahan, sektor pertanian, sektor perkebunan, sektor peternakan, sektor perikanan, dan sektor jasa. Kontribusi sektor perdagangan terhadap PDB pada tahun 2016 sebesar $12,98 \%$ atau menjadi penyumbang ketiga terbesar bagi PDB (BPS Jabar, 2016). Kontribusi sektor perdagangan terhadap PDRB Jawa Barat sebesar 15,21\% pada tahun 2015 (BPS Jabar, 2016). Hal tersebut membuat sektor perdagangan merupakan penyumbang kedua terbesar bagi PDRB Jawa Barat. Kontribusi sektor pertanian terhadap PDB pada tahun 2016 sebesar 14,42\% (BPS Jabar, 2016). Kontribusi sektor pertanian terhadap PDRB Jawa Barat 2015 sebesar 7,71\% (BPS Jabar, 2016). CV Diana Phon Bogor memerlukan strategi yang tepat untuk meningkatkan kembali penjualannya. Salah satu strategi yang penting untuk dianalisis yaitu strategi pemasaran, karena secara langsung terkait dengan penjualan yang dilakukan oleh suatu usaha. Kusnawan dan Wijoyo (2008) mengungkapkan bahwa pemasaran merupakan salah satu hal yang harus dilakukan oleh para pengusaha untuk dapat mengembangkan dan mempertahankan bisnis, serta mendapatkan laba. Pemasaran merupakan suatu proses sosial dan manajerial yang dilakukan oleh individu maupun kelompok untuk memenuhi kebutuhan dan keinginan, dimana produk-produk nilai diciptakan, ditawarkan dan dipertukarkan. Pemasaran memiliki beberapa peranan, salah satunya merumuskan dan mengimplementasikan program-program pemasaran yang didasarkan pada bauran pemasaran. Pemasaran juga mengelola hubungan-hubungan yang harmonis dengan pelanggan dan pemasok (Kotler, 2012).

Strategi pemasaran yang saat ini digunakan mengacu pada bauran pemasaran yaitu seperangkat keputusan operasional mengenai keputusan produk, harga, promosi, dan tempat. Tabel 2 menunjukkan strategi pemasaran yang digunakan oleh CV Diana Phon Bogor.

Tabel 2. Strategi pemasaran CV Diana Phon Bogor saat ini

\begin{tabular}{ll}
\hline \multicolumn{1}{c}{$\begin{array}{c}\text { Bauran } \\
\text { pemasaran }\end{array}$} & \multicolumn{1}{c}{ Strategi } \\
\hline Produk & Diferensiasi produk \\
Harga & Penetapan harga berdasarkan biaya \\
Tempat & $\begin{array}{l}\text { Berhubungan dengan saluran } \\
\text { distribusi, pemilihan saluran distribusi } \\
\text { berdasarkan } \\
\end{array}$ \\
pertimbangan perusahaan \\
Promosi & Periklanan, pameran \\
\hline
\end{tabular}

Diferensiasi produk yang dimaksud adalah dalam hal merek. Satu jenis produk memiliki bermacam merek, misalnya insektisida yang ditawarkan memiliki merek Amabas, Curacron, Decis, dan Regent. Biaya yang dimaksud terdiri dari harga yang ditawarkan oleh pemasok dan laba yang ditentukan berdasarkan cepat atau lambatnya produk terjual. Saluran distribusi yang dimiliki oleh usaha kecil ini termasuk pendek yaitu dimulai dari pemasok, pengecer, dan ke konsumen. Saat ini CV Diana Phon Bogor sudah tidak melakukan promosi.

Penelitian ini menggunakan pendekatan stakeholder engagement strategy yang dipopulerkan oleh BSR (Business for Social Responsibility) (Morris dan Farid, 2012). Stakeholder engagement merupakan proses dimana suatu perusahaan melibatkan orang-orang yang mungkin akan terpengaruh oleh keputusan yang dibuat perusahaan, atau dapat mepengaruhi pelaksanaan keputusan yang dibuat (Susilo et al., 2016). Stakeholder engagement strategy menunjukkan bagaimana perusahaan dapat berinisiasi dan membangun hubungan yang berkelanjutan bagi perusahaan (Morris dan Farid, 2012). Penggunaan stakeholder engagement strategy pada penelitian ini masih tergolong baru. Penelitian dahulu mengenai strategi pemasaran umumnya menggunakan bauran pemasaran dan STP (Segmentasi, Targeting, Positioning). Sementara stakeholder engagement strategy umumnya digunakan perusahaan untuk program CSR (Corporate Social Responsibility) (Morris dan Farid, 2012). Selain itu saat ini pemasaran tidak hanya berfokus pada produk yang dibutuhkan konsumen dan kepuasan konsumen. Pemasaran saat ini juga berfokus pada membangun hubungan dengan konsumen. Penelitian dengan pendekatan stakeholder engagement strategy dapat melihat keterlibatan antara perusahaan, konsumen, dan pemasok.

Stakeholder engagement strategy merupakan pengembangan dari stakeholder theory yang dikemukakan oleh Edward Freeman pada 1984 (Freeman et al., 2010). Stakeholder engagement melibatkan interaksi pemangku kepentingan sebuah 
perusahaan dengan grup tertentu diluar perusahaan. Stakeholder engagement yang efektif bergantung pada rasa saling percaya, rasa hormat, dan komunikasi yang transparan antara perusahaan dan pemangku kepentingan [Dundee Precious Metals Krumovgrad, 2014]. Publikasi yang ditulis oleh BRD (Better Regulation Division) menjelaskan terdapat beberapa tahapan pada stakeholder engagement yaitu inform, consult, involve, collaborate, dan empower (BRD, 2016). BRD merupakan bagian dari divisi keuangan, pelayanan, dan inovasi pada Pemerintahan New South Wales.

Beberapa penelitian yang berkaitan dengan stakeholder engagement yaitu Herremans et al. (2016) mengungkapkan terdapat tiga tipe stakeholder yaitu pasar modal, stakeholder internal dan eksternal, dan pasar politik dan sosial. Perusahaan memiliki strategi stakeholder engagement yang berbeda untuk masing-masing tipe. Felsen dan Nastanski (2017) mengungkapkan bahwa stakeholder engagement membantu mewujudkan keberhasilan strategi organisasi. Susilo et al. (2016) menjelaskan bahwa pendekatan stakeholder engagement telah menunjukkan bagaimana relasi organisasi dengan stakeholder terkait.

Penelitian yang berkaitan dengan strategi pemasaran khususnya yang menggunakan pendekatan bauran pemasaran antara lain Obasan et al. (2015) menjelaskan bahwa terdapat hubungan yang positif antara strategi pemasaran dengan nilai produk, yaitu nilai produk dapat ditingkatkan dengan startegi pemasaran. Pamudji (2015) menyatakan bahwa prioritas startegi yang digunakan untuk usaha yang sudah tertinggal dari perubahan yang terjadi di lingkungan bisnisnya yaitu dengan penetrasi pasar, diferensiasi produk, penjualan langsung, dan cakupan distribusi. Rachmawati (2011) mengungkapkan bahwa bauran pemasaran mampu menciptakan loyalitas pelanggan. Selang (2013) menjelaskan bahwa secara simultan produk, harga, promosi, dan tempat berpengaruh signifikan terhadap loyalitas konsumen.

Secara lebih ringkas permasalahan yang dihadapi CV Diana Phon Bogor yaitu penurunan penjualan pada 2014-2016. Melemahnya perekonomian Indonesia pada 2012-2016 mengakibatkan daya beli masyarakat menurun, sehingga berdampak pada penurunan penjualan pada usaha-usaha seperti CV Diana Phon Bogor. CV Diana Phon Bogor masih memiliki potensi untuk meningkatkan penjualan kembali. Tujuan penulisan karya ilmiah ini yaitu untuk merancang strategi pemasaran CV Diana Phon Bogor menggunakan pendekatan stakeholder engagement strategi.

\section{METODE PENELITIAN}

Penelitian ini dilakukan di CV Diana Phon Bogor yaitu di Jalan Otto Iskandardinata No. 56,
Bogor, Jawa Barat. Penelitian ini menggunakan pendekatan deskriptif. Pendekatan deskriptif adalah pencarian fakta dengan interpretasi yang tepat dan mempelajari situasi tertentu termasuk hubungan, kegiatan, dan pandangan (Creswell, 1998). Hasil wawancara dengan pemilik usaha dan karyawan serta hasil kuisioner dijelaskan secara deskriptif namun tetap mengacu pada data yang relevan. Kegiatan pengambilan data dilaksanakan mulai bulan Agustus 2017 sampai dengan Oktober 2017. Jenis data yang digunakan yaitu data primer dan data sekunder. Data primer diperoleh melalui wawancara narasumber, yaitu pemilik dan karyawan CV Diana Phon Bogor dan kuisioner, yaitu konsumen dan pemasok CV Diana Phon Bogor. Data sekunder diperoleh dari studi kepustakaan dengan mempelajari dan menelaah berbagai literatur yang berhubungan dengan penelitian.

Wawancara dilakukan secara semi-struktur. Pengambilan sampel kuisioner untuk konsumen menggunakan metode accidental sampling (pengambilan sampel dengan memilih siapa yang kebetulan dijumpai). Sementara pengambilan sampel kuisioner untuk pemasok menggunakan metode puposive sampling. Perbedaan pengambilan sampel pada kuisioner karena kosumen yang berbelanja di CV Diana Phon Bogor tidak tetap atau berubah-ubah baik dalam jumlah maupun identitas konsumen, sementara pemasok yang memasok ke CV Diana Phon Bogor memiliki jumlah dan identitas yang tetap. Jumlah responden pada kuisinoer untuk konsumen yaitu 30 responden. Hal tersebut didasarkan pada pendapat Gay dan Diehl (1992) dimana ukuran minimum sampel yang dapat diterima berdasarkan desain penelitian yang digunakan, dalam hal ini penelitian deskriptif korelasi yaitu minimal 30 subjek. Jumlah pemasok yang memasok ke CV Diana Phon Bogor yaitu 6 pemasok. Tabel 3 menunjukkan data dan narasumber yang digunakan dalam penelitian ini.

Perancangan strategi pemasaran dengan menggunakan pendekatan stakeholder engagement strategy terdiri dari beberapa tahapan, yaitu (Morris dan Farid, 2012):

1. Menjabarkan stakeholder yang terlibat dengan CV Diana Phon Bogor.

2. Mengelompokkan stakeholder tersebut ke kuadran stakeholder engagement. Pengelompokkan tersebut diperoleh melalui hasil kuisioner. Kuisioner tersebut berisi lima atribut yaitu:

a. kontribusi menjelaskan seberapa besar stakeholder memiliki informasi, masukan, dan kepakaran dalam topik atau isu yang berhubungan dengan tujuan perusahaan,

b. legitimasi menjelaskan seberapa legal hubungan kerjasama yang terjalin,

c. kesediaan untuk terlibat merupakan seberapa besar stakeholder bersedia untuk terlibat. Bagi konsumen lebih kepada kesediaan untuk belanja kembali, 
Tabel 3. Data dan narasumber CV Diana Phon Bogor

\begin{tabular}{|c|c|c|c|c|}
\hline \multirow{2}{*}{$\begin{array}{l}\text { No } \\
1\end{array}$} & \multirow{2}{*}{$\begin{array}{r}\text { Data } \\
\text { Primer }\end{array}$} & \multirow{2}{*}{$\begin{array}{l}\text { Metode Pengambilan } \\
\text { Data } \\
\text { Wawancara Semi- } \\
\text { struktur }\end{array}$} & \multicolumn{2}{|c|}{ Narasumber } \\
\hline & & & 1. Pemiliki CV Diana Phon Bogor & Rusdi Jafar \\
\hline & & & 2. Manajer CV Diana Phon Bogor & Siti Latifah \\
\hline & & Kuisioner & 1. Pemasok & $\begin{array}{l}\text { 1. Gudang (Pusat) } \\
\text { 2. PT Intrasari Raya } \\
\text { 3. BLST } \\
\text { 4. CV Mangkubumi } \\
\text { Perkasa } \\
\text { 5. Toko Sanjaya } \\
\text { 6. Pak Go }\end{array}$ \\
\hline 2 & Sekunder & Studi Literatur & $\begin{array}{l}\text { 2. Konsumen } \\
\text { Laporan penjualan tahunan } \mathrm{CV} \\
\text { Diana Phon Bogor }\end{array}$ & \\
\hline
\end{tabular}

d. pengaruh menunjuKkan seberapa besar pengaruh atau peran stakeholder terhadap bisnis tersebut, dan

e. kepentingan keterlibatan merupakan peluang seberapa besarnya stakeholder dapat mengganggu kelangsungan bisnis.

Berikut merupakan pemetaan stakeholder dalam Stakeholder Engagement (SE):

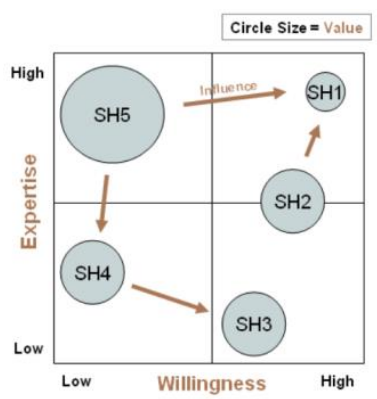

(Sumber: Morris dan Farid, 2012)

Gambar 1. Pemetaan hasil penilaian atribut

Masing-masing stakeholder kemudian dipetakan berdasarkan tiga kategori yaitu kategori inform, communicate, dan engage. Dalam pemetaan ini, nilai atribut kontribusi dan atribut legitimasi dirata-ratakan menjadi aspek kepakaran (expertise) pada sumbu vertikal. Nilai atribut kesediaan untuk terlibat dipetakan menjadi aspek kesediaan (willingness) pada sumbu horisontal. Atribut pengaruh dan atribut kepentingan keterlibatan dirataratakan menjadi aspek nilai yang diwakili oleh ukuran lingkaran dari stakeholder tersebut. Gambar 2 merupakan penggolongan pemetaan kuadran.

3. Merancang strategi pemasaran berdasarkan stakeholder yang telah dikelompokkan menjadi tiga kategori. Kategori engage, communicate, dan inform secara berurutan menunjukkan hubungan yang kuat, sedang, dan lemah terhadap CV Diana Phon Bogor.

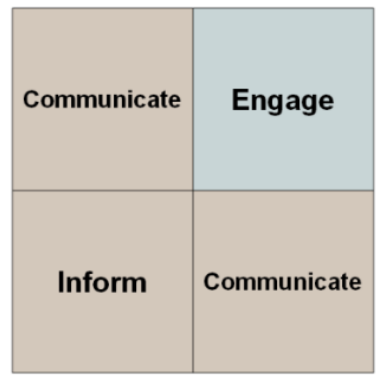

(Sumber: Morris dan Farid, 2012)

Gambar 2. Pemetaan kuadran stakeholder

\section{HASIL DAN PEMBAHASAN}

\section{Analisis Stakeholder}

Tahap analisis stakeholder dilakukan dengan mengumpulkan penilaian atas masingmasing stakeholder berdasarkan kelima atribut yang telah ditetapkan. Kelima atribut tersebut yaitu atribut kontribusi, legitimasi, kesediaan untuk terlibat, pengaruh, dan kepentingan keterlibatan. Kelima atribut tersebut kemudian dikelompokan menjadi tiga atribut yaitu atribut expertise, willingnes, dan value. Expertise berasal dari nila rata-rata atribut kontribusi dan legitimasi. Value berasal dari nilai rata-rata atribut pengaruh dan kepentingan keterlibatan. Sementara willingness merupakan nilai dari atribut kesediaan untuk terlibat.

Langkah berikunya dibuat diagram scatter pada ketiga atribut yaitu expertise, willingness, dan value dengan menggunakan software XLStat. Software XLStat mampu memvisualisasikan data yang terdapat pada software Microsoft Excel. Pada diagram scatter, atribut willingnes dijadikan sebagai sumbu horizontal sementara atribut expertise dijadikan sebagai sumbu vertikal. Atribut value digambarkan dengan besar ukuran lingkaran stakeholder. Gambar 3 merupakan pemetaan SM (Stakeholder Mapping) untuk stakeholder pemasok: 


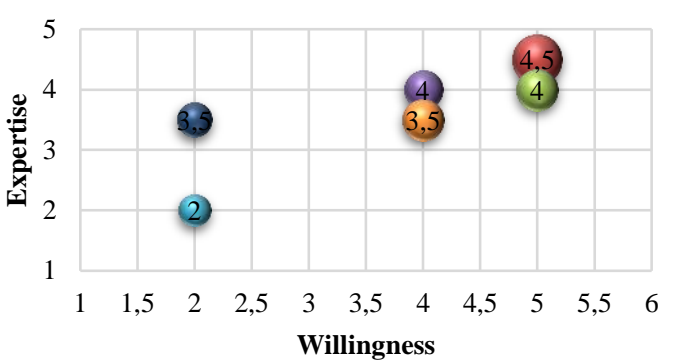

$\begin{array}{ll}\text { - Gudang (Pusat) } & \text { • PT Intrasari Raya } \\ \text { - BLST } & \text { Pak GO } \\ \bullet \text { CV Mangkubumi Perkasa } & \text { Toko Sanjaya }\end{array}$

Gambar 3. Pemetaan stakeholder pemasok

Terdapat empat kuadran dalam pemetaan stakeholder tersebut yaitu kuadran I, II, III, dan IV. Kuadran I memiliki nilai atribut willingness dan expertise rendah. Kuadran II memiliki nilai atribut willingness tinggi dan expertise rendah. Kuadran III memiliki nilai atribut willingness rendah dan expertise tinggi. Kuadran IV memiliki nilai atribut willingness dan expertise tinggi.

Berdasarkan hasil diagram scatter pada Gambar 3, pemasok Gudang (Pusat), PT Intrasari Raya, BLST, dan CV Mangkubumi Perkasa masuk ke kuadran IV yaitu memiliki nilai atribut willingness dan expertise tinggi. Gudang (Pusat) merupakan pemasok utama pada CV Diana Phon Bogor sehingga memiliki nilai atribut value terbesar yaitu 4,5. PT Intisari Raya dan BLST memiliki nilai atribut value sebesar 4. CV Mangkubumi Perkasa dan Toko Sanjaya memiliki nilai atribut value sebesar 3,5. Toko Sanjaya berada pada kuadran III. Pak Go masuk ke kuadran I dan memiliki nilai atribut value sebesar 2 .

CV Mangkubumi Perkasa dan Toko Sanjaya memiliki nilai atribut value yang sama, namun keduanya berada pada kuadran yang berbeda. CV Mangkubumi Perkasa memiliki nilai atribut willingness yang lebih besar dari Toko Sanjaya. Hal tersebut dikarenakan CV Mangkubumi Perkasa memiliki jenis usaha yang relatif sama dengan $\mathrm{CV}$ Diana Phon Bogor. Sementara Toko Sanjaya memiliki jenis usaha material. Pak Go merupakan pemasok yang menjual produknya dengan cara berkeliling, sehingga tidak memiliki bangunan fisik yang tetap untuk menjual produknya. Pengetahuan Pak Go mengenai produk-produk yang ditawarkan oleh CV Diana Phon Bogor tergolong rendah, karena produk yang dijual Pak Go hanya gelang cangkul yang ia buat sendiri. Begitu pula keinginan untuk terlibat (willingness) dengan CV Diana Phon Bogor. Produk yang ditawarkan Pak Go bukan produk yang sering habis terjual di CV Diana Phon Bogor, sehingga willingness Pak Go yang tegolong rendah tidak menjadi masalah bagi CV Diana Phon Bogor.

Pemasok yang memiliki loyalitas tinggi yaitu Gudang (Pusat), PT Intrasari Raya, BLST, dan
CV Mangkubumi Perkasa. Hal tersebut karena nilai atribut willingness dan expertise yang dimiliki tinggi atau biasa disebut engage. Morris dan Farid (2012) menjelaskan bahwa stakeholder yang berada pada kategori engage adalah yang harus dijadikan prioritas utama oleh perusahaan. Proses bisnis yang terjadi pada CV Diana Phon Bogor akan terganggu apabila salah satu pemasok yang ada di kategori engage tidak ingin bekerja sama lagi dengan CV Diana Phon Bogor.

Pemasok yang memiliki loyalitas sedang yaitu Toko Sanjaya. Morris dan Farid (2012) mengatakan stakeholder yang memiliki loyalitas sedang atau berada pada kategori communicate adalah stakeholder potensial. Stakeholder potensial dapat masuk ke kategori engage apabila CV Diana Phon Bogor dapat meningkatkan pelayanannya. Gambar 3 menunjukkan bahwa Toko Sanjaya memiliki keinginan untuk bekerja sama yang rendah. Pemasok yang memiliki loyalitas rendah yaitu Pak Go. Pak Go berada pada kategori inform yaitu stakeholder dengan prioritas rendah. Prioritas rendah artinya Pak Go tidak memiliki pengetahuan akan CV Diana Phon Bogor maupun terlibat lebih jauh dengannya. CV Diana Phon Bogor harus bekerja lebih keras apabila menginginkan Pak Go masuk pada kategori communicate ataupun engage. CV Diana Phon Bogor juga harus memperhatikan hal lain khususnya dalam hal usaha yang dilakukan harus sebanding atau lebih baik dengan hasil yang didapatkan.

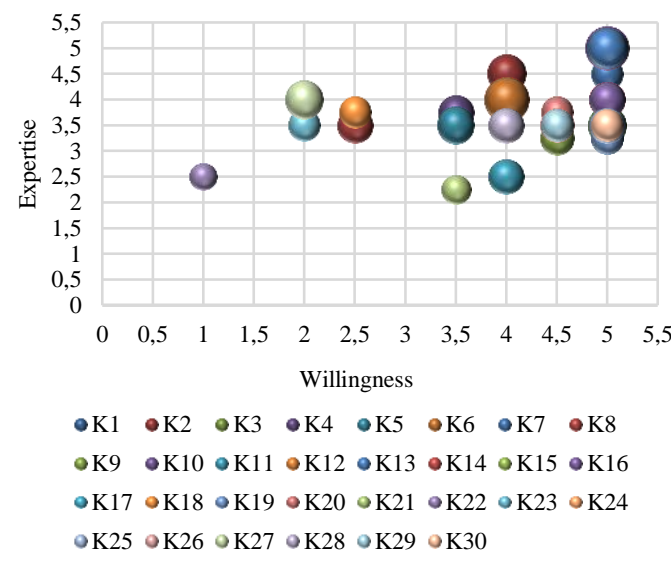

Gambar 4. Pemetaan stakeholder konsumen

Gambar 4 menunjukkan pemetaan stakeholder konsumen pada CV Diana Phon Bogor. Sebagian besar responden masuk pada kategori engage yaitu yang memiliki loyalitas tinggi dan dijadikan prioritas utama. Responden yang masuk kategori engage sebesar 76,7\%. Responden yang masuk kategori communicate atau loyalitas sedangsebesar 20\%. Responden yang masuk kategori inform atau loyalitas rendah sebesar 3,3\%. 


\section{Stakeholder Engagement}

Hasil pemetaan stakeholder engagement menunjukan terdapat 27 stakeholder yang masuk kategori engage. Stakeholder tersebut terdiri dari 4 stakeholder pemasok dan 23 stakeholder konsumen. Stakeholder pemasok yang masuk kategori engage terdiri dari Gudang (Pusat), BLST, PT Intrasari Raya, dan CV Mangkubumi Perkasa. Dua puluh (20) stakeholder konsumen merupakan responden yang sudah mengetahui jenis dan harga produk yang ditawarkan oleh CV Diana Phon Bogor. Pengetahuan responden mengenai jenis dan harga produk didapatkan karena frekuensi belanja di CV Diana Phon Bogor yang relatif tinggi. Secara umum, konsumen yang masuk kategori engage adalah pelanggan CV Diana Phon Bogor.

Stakeholder yang terdapat di kategori communicate terdiri dari 7 stakeholder. Stakeholder tersebut berasal dari 1 stakeholder pemasok yaitu Toko Sanjaya dan 6 stakeholder konsumen. Namun stakeholder-stakeholder tersebut berada di kuadran berbeda. Dua berada di kuadran II, yaitu stakeholder memiliki nilai atribut willingnes tinggi namun expertise rendah. Lima berada di kuadran III, yaitu stakeholder memiliki nilai atribut willingnes rendah namun expertise tinggi. Terdapat 2 stakeholder yang masuk kategori inform, yaitu satu dari stakeholder pemasok dan satu lagi dari konsumen. Pemasok yang masuk di kategori inform yaitu Pak Go. Konsumen yang masuk kategori inform merupakan konsumen yang baru pertama kali berbelanja di CV Diana Phon Bogor. Sebagian besar stakeholder yang terlibat dengan CV Diana Phon Bogor termasuk loyal dan menjadi prioritas utama.

Pengelompokkan stakeholder tersebut bertujuan untuk memudahkan perusahaan, dalam hal ini CV Diana Phon Bogor, dalam merancang strategi pemasaran. Strategi pemasaran tersebut nantinya diharapkan dapat meningkatkan penjualan CV Diana Phon Bogor, seperti yang menjadi permasalahan CV Diana Phon bogor, yaitu penurunan penjualan dalam kurun waktu tiga tahun terakhir (2014- 2016).

\section{Rancangan Strategi Pemasaran CV Diana Phon Bogor}

Perancangan strategi pemasaran bertujuan untuk meningkatkan penjualan CV Diana Phon Bogor. Perancangan strategi pemasaran ini berdasarkan faktor-faktor yang mempengaruhi penjualan, strategi pemasaran yang digunakan saat ini dan stakeholder engagement strategy. Hasil dari stakeholder engagement yaitu sebagian besar stakeholder yang terlibat dengan CV Diana Phon Bogor termasuk loyal dan menjadi prioritas utama.

Faktor yang menyebabkan turunnya penjualan CV Diana Phon Bogor yaitu sistem penjualan yang masih menerapkan pembayaran tunai kepada konsumen. Usaha ini tidak menyediakan pembayaran non tunai seperti penggunaan kartu debit dan kartu kredit. Berdasarkan hasil survei yang dilakukan oleh penyedia teknologi pembayaran (Visa), $80 \%$ responden lebih senang menggunakan kartu pembayaran elektronik (Kompas, 2017). Hasil survei tersebut naik sebesar 69\% dari tahun 2015 . Selain itu hasil survei juga menunjukkan sebesar $34 \%$ responden lebih sedikit membawa uang tunai dibandingkan lima tahun lalu. Beralihnya tren pembayaran menjadi non tunai disebabkan transaksi non tunai memiliki beberapa kelebihan yaitu lebih praktis, hemat ruang, lebih aman, lebih nyaman, dan lebih transparan. Survei yang dilakukan oleh penyedia teknologi pembayaran (Visa) menunjukan bahwa masalah keamanan merupakan salah satu faktor yang membuat masyarakat berpindah menggunakan kartu pembayaran elektronik (Kompas, 2017). CV Diana Phon Bogor dapat secara bertahap memperluas jenis alat pembayaran yang dimilikinya. Sehingga konsumen memiliki pilihan dalam melakukan pembayaran. Hal tersebut nantinya diharapkan mampu meningkatkan penjualan $\mathrm{CV}$ Diana Phon Bogor.

Kegiatan jual beli yang ada di CV Diana Phon Bogor terjadi secara langsung. Penjual dan pembeli bertemu di tempat yang sama, dimana terdapat produk-produk yang diperjual belikan. Konsumen yang datang membeli produk tersebut sebagian besar berdomisili di daerah Kota Bogor dan sekitarnya. CV Diana Phon Bogor dapat menjangkau konsumen ke daerah yang lebih luas dengan berjualan online. Hal tersebut karena dalam kurun waktu sepuluh tahun terakhir industri e-commerce di Indonesia tumbuh sebesar 17\% (BPS, 2016). Beberapa alasan industri e-commerce Indonesia akan terus mengalami peningkatan yaitu bertumbuhnya penggunaan telepon pintar atau smartphone dan penetrasi internet di Indonesia. Penggunaan internet di Indonesia pada 2016 sebesar \pm 82 juta orang atau $30 \%$ dari total penduduk Indonesia. Sebesar $73 \%$ pengguna internet di Indonesia mengakses internet melalui telepon pintar atau smartphone (Das et al., 2016)

Siswanto (2013) juga mengatakan bahwa media sosial dapat menarik konsumen baru. Hal lainnya dikatakan pula oleh Sutejo (2006) bahwa penggunaan internet dalam dunia pemasaran membawa perubahan baru. Perubahan tersebut dapat terlihat dari bauran pemasaran (4P), dimana pelaku usaha dapat mengetahui lebih cepat produk yang diinginkan dan dibutuhkan konsumen (Produk), pemasaran daring meningkatkan kompetisi dan standar akan harga produk yang ditawarkan (Harga), promosi yang dilakukan lebih kearah komunikasi yang interaktif antar pelaku usaha dengan konsumen (Promosi), dan mengurangi tempat penyimpanan bagi pelaku usaha yang belum memiliki tempat usaha (Tempat). Penjualan secara online diharapkan mampu meningkatkan penjualan CV Diana Phon Bogor. Dalam laporan McKinsey yang berjudul Unlocking Indonesia's Digital Opportunity menyebutkan beralihnya industri perdagangan ke 
ranah digital akan meningkatkan pertumbuhan ekonomi hingga US \$ 150 milyar pada 2025 (Das et al., 2016).

Strategi pemasaran yang dapat dilakukan oleh CV Diana Phon Bogor berdasarkan penjelasan yang sudah dijelaskan yaitu dengan menjaga hubungan baik dengan pemasok dan konsumen. Hal ini karena sebagian besar stakeholder berada pada kategori engage. Strategi pemasaran lainnya yaitu dengan meningkatkan pelayanan untuk konsumen. Peningkatan pelayanan yang dilakukan berupa memperluas jenis alat pembayaran, menyediakan layanan pengiriman barang, dan membuka toko online untuk menarik konsumen baru. Gambar 5 menunjukkan rancangan strategi pemasaran untuk CV Diana Phon Bogor.

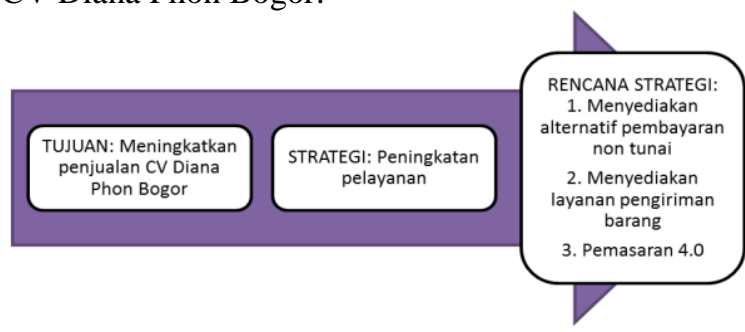

Gambar 5. Rancangan strategi pemasaran CV Diana Phon Bogor

Gambar 5 menunjukkan implikasi manajerial CV Diana Phon Bogor. Tujuan utama pada penelitian ini yaitu membuat strategi pemasaran agar dapat meningkatkan kembali penjualan CV Diana Phon Bogor. Strategi pemasaran yang dilakukan yaitu strategi peningkatan pelayanan. Peningkatan pelayanan yang dilakukan terdiri dari tiga hal yaitu menyediakan alternatif pembayaran non tunai, menyediakan layanan pengantaran barang, dan membuka toko online dengan pemasaran 4,0 .

Layanan pengiriman barang yang dilakukan yaitu dengan bekerja sama dengan pihak ke tiga. Hal tersebut karena terbatasnya sumberdaya manusia dan sumberdaya modal yang dimiliki oleh CV Diana Phon Bogor. Kerjasama dengan pihak ke tiga dapat menjadi alternatif dalam penyediaan layanan pengiriman barang. CV Diana Phon Bogor tidak harus mencari karyawan baru yang dapat mengemudikan sebuah kendaraan, serta tidak perlu menyediakan transportasi untuk pengiriman barang. Hal ini membuat modal yang dimiliki CV Diana Phon Bogor dapat digunakan untuk keperluan pembelian produk-produk.

Pemasaran 4,0 adalah pendekatan pemasaran yang mengkombinasikan interaksi offline dan online antara perusahaan dengan konsumen. Pemasaran 4,0 merupakan pengembangan pemasaran paling baru dari pendekatan pemasaran sebelumnya. Pemasaran 1,0 lebih berorintasi pada produk, sehingga tujuan perusahaan adalah menghasilkan produk yang dibutuhkan konsumen. Pemasaran 2,0 mulai berorientasi pada konsumen, dimana perusahaan mulai memikirkan kepuasan konsumen. Pemasaran 3,0 selain memikirkan produk dan kepuasan konsumen, pada pendekatan ini juga mencoba menarik sisi spritiul konsumen. Pemasaran 4,0 memfokuskan pada membangun hubungan dengan konsumen.

Hal yang dilakukan pada pemasaran 4,0 yaitu dengan memanfaatkan teknologi internet. Pemanfaatan teknologi internet dapat melalui website, email, dan media sosial. Salah satu hal menarik dari media sosial adalah adanya social media influencer. Social media influencer adalah orang-orang yang memiliki pengikut atau followers yang banyak di media sosial, sehingga dapat memberikan pengaruh yang besar bagi pengikutnya. Pemanfaatan social media influencer dapat menjadi strategi pemasaran yang menarik untuk mencari konsumen baru. Hal ini nantinya dapat meningkatkan kembali penjualan CV Diana Phon Bogor.

\section{KESIMPULAN DAN SARAN}

\section{Kesimpulan}

Hasil analisis stakeholder menyatakan bahwa pemangku kepentingan yang terlibat dengan CV Diana Phon Bogor sebagian besar masuk ke kategori engage. Pemasok yang masuk ke kategori engage sebesar $66,7 \%$ dan konsumen yang masuk ke kategori engage sebesar 76,7\%. Hasil tersebut menunjukan bahwa sebagian besar pemangku kepentingan yang terlibat dengan CV Diana Phon Bogor adalah loyal dan menjadi prioritas utama. Perancangan strategi pemasaran yang dilakukan oleh CV Diana Phon yaitu menjaga hubungan baik dengan pemangku kepentingan dalam hal ini pemasok dan konsumen. Selain itu CV Diana Phon Bogor harus meningkatkan pelayanan yang diberikan kepada konsumen. Beberapa pelayanan yang perlu ditingkatkan yaitu dalam hal sistem pembayaran dan membuka toko online dengan pendekatan pemasaran 4,0. Membuka toko online bertujuan untuk menarik konsumen baru secara lebih luas.

\section{Saran}

Perancangan strategi pemasaran pada penelitian ini menggunakan pendekatan stakeholder engagement strategy yang dipopulerkan oleh BSR (Business for Social Responsibility). Namun demikian, penelitian ini tidak seluruhnya menggunakan tahapan yang ada pada pendekatan tersebut. Oleh karena itu, penelitian selanjutnya diharapkan dapat meneliti dengan mengikuti keseluruhan tahapan pada stakeholder engagement strategy.

\section{DAFTAR PUSTAKA}

[BPS Jabar] Badan Pusat Statistik Provinsi Jawa Barat. 2016. Provinsi Jawa Barat dalam 
angka 2016. Bandung : BPS Provinsi Jawa Barat.

[BPS] Badan Pusat Statistik. 2015. Pertumbuhan Ekonomi Indonesia Tahun 2014 Tumbuh 5.02 persen, Melambat Sejak Lima Tahun Terakhir. Jakarta: BPS.

[BPS] Badan Pusat Statistik. 2016. Ekonomi Indonesia triwulan IV 2015 tumbuh 5.04 persen tertinggi selama tahun 2015. Jakarta: BPS.

[BPS] Badan Pusat Statistik. 2016. Hasil pendaftaran (listing) usaha/ perusahaan Sensus Ekonomi 2016. Jakarta: BPS.

[BRD] Better Regulation Division. 2016. Better regulation stakeholder engagement strategy. Sydney: NSW Government Publication.

[Dundee Precious Metals Krumovgrad]. 2014. Stakeholder engagement plan: Krumovgrad gold project. Krumovgrad: Dundee Precious Metals Krumovgrad Press.

[Investor Daily Indonesia]. 2018. Ekonomi 20142017. www.beritasatu.com. [16 Januari 2018].

[Kemenperin RI] Kementerian Perindustrian Republik Indonesia. 2016. Kontribusi UMKM naik. www.kemenperin.go.id. [25 Januari 2017].

[Kompas1]. 2017. Survei: 80 persen orang Indonesia lebih suka transaksi non tunai. www.kompas.com [9 Januari 2018].

[Kompas2]. 2017. Pengguna non tunai semakin banyak. www.pressreader.com. [9 Januari 2018].

Das K, Gryseels M, Sudhir P, Khoon TT. 2016. Unlocking Indonesia's digital opportunity. Jakarta: McKinsey and Company.

Felsen D dan Nastanski M. 2017. The process of stakeholder engagement: the case of establishing advisory councils at a school of business. IJAS.9(4): 655-668.

Freeman RE, Harrison JS, Wicks AC, Parmar B, DeColle S. 2010. Stakeholder Theory: The State of The Art. Cambridge : Cambridge University Press.
Gay LR dan Diehl PL. 1992. Research Methods for Business and Management. New York: Mc Millan Publishing Company.

Herremans IM, Nazari JA, dan Mahmoudian F. 2016. Stakeholder relationship, engagement, and sustainability reporting. Journal Business Ethics. 138: 417-435.

Kotler P. 2012. Marketing Management. $14^{\text {th }}$ ed. London: Pearson.

Kusnawan K dan Wijoyo P. 2008. Pengaruh strategi bauran pemasaran (marketing mix) terhadap efektivitas volume penjualan sayuran hidroponik. AGRISE. 8(2): 97-103.

Morris J dan Farid B. 2012. Back To Basics: How To Make Stakeholder Engagement Meaningful For Your Company. San Fransisco: BSR.

Obasan KA, Ariyo OO, dan Hassan BA. 2015. Marketing strategy and product performance a study of selected firms in Nigeria. EJESM. 8(6): 669 - 674.

Pamudji WH. 2015. Strategi pemasaran minuman teh dalam kemasan pada CV Fresbrew Mels Beverages. [Tesis]. Bogor: Institut Pertanian Bogor.

Rachmawati R. 2011. Peranan bauran pemasaran (marketing mix) terhadap peningkatan penjualan (sebuah kajian terhadap bisnis restoran). Jurnal Kompetensi Teknik. 2(2): 143-150.

Selang CAD. 2013. Bauran pemasaran (marketing mix) pengaruhnya terhadap loyalitas konsumen pada fresh mart Bahu Mall Manado. Jurnal EMBA.1(3) : 71-80.

Siswanto T. 2013. Optimalisasi sosial media sebagai media pemasaran usaha kecil menengah. Jurnal Liquidity.2(1): 80-86.

Susilo ME, Prayudi, dan Erawati H. 2016. Pendekatan stakeholder engagement dalam pengembangan desa wisata. Jurnal Ilmu Komunikasi.14(2) : 122-135.

Sutejo BS. 2006. Internet marketing: Konsep dan persoalan baru dunia pemasaran. Jurnal Manajemen.6(1): 41-57. 